\title{
Império Romano - estrutura e funcionamento da Educação
}

\author{
Roman Empire - structure and functioning of Education \\ Imperio Romano - estructura y funcionamiento de la Educación
}

Recebido: 21/08/2021 | Revisado: 26/08/2021 | Aceito: 10/01/2022| Publicado: 14/01/2022

\author{
Adelcio Machado dos Santos \\ ORCID: https://orcid.org/0000-0003-3916-972X \\ Universidade Alto Vale do Rio do Peixe, Brasil \\ E-mail: adelcio@uniarp.edu.br \\ Rubens Luís Freiberger \\ ORCID: https://orcid.org/0000-0002-1520-1580 \\ Universidade Alto Vale do Rio do Peixe, Brasil \\ E-mail: rubens.freiberger@gmail.com \\ Dreone Mendes \\ ORCID: https://orcid.org/0000-0002-6150-0450 \\ Universidade Alto Vale do Rio do Peixe, Brasil \\ E-mail: dreone@gmail.com
}

\begin{abstract}
Resumo
O Direito Romano, um dos mananciais da civilização ocidental, consiste no complexo de normas vigentes em Roma, que durante os treze séculos da história romana. Regeu a modificação constante na estrutura do Império Romano, conforme a evolução da cultura e as alterações políticas, econômicas e sociais, que o caracterizam. $\mathrm{O}$ artigo pretende projetar luz sobre a estrutura e funcionamento da educação romana. Para tanto, adotou-se a pesquisa qualitativa, de revisão bibliográfica sistemática. Conclui-se que a estrutura compreende os dois graus tradicionais de gramática e retórica, no curso de gramática, ensina-se a língua latina e a língua grega e as noções precisas para este fim, no curso de retórica, lecionava-se a interpretação dos historiadores e dos oradores, as normas e as exercitações de eloquência ocupam um lugar de destaque, ademais os romanos souberam transmitir a prática dos ideais do respeito aos direitos individuais e à liberdade política, do cultivo da moralidade pessoal e coletiva, da excelência social a que se denomina cultura.
\end{abstract}

Palavras-chave: Direito Romano; Império Romano; Educação.

\begin{abstract}
Roman Law, one of the springs of Western civilization, consists of the complex of rules in force in Rome during the thirteen centuries of Roman history. It governed the constant modification in the structure of the Roman Empire, according to the evolution of culture and the political, economic and social changes that characterized it. The article intends to shed light on the structure and functioning of Roman education. To this end, qualitative research was adopted, with a systematic bibliographic review. It is concluded that the structure comprises the two traditional degrees of grammar and rhetoric, in the grammar course, the Latin and Greek languages and the precise notions for this purpose are taught, in the rhetoric course, the interpretation of historians and orators is taught, the rules and the eloquence exercises occupy a prominent place, moreover the Romans knew how to transmit the practice of the ideals of respect for individual rights and political freedom, of the cultivation of personal and collective morality, of social excellence which is called culture.
\end{abstract}

Keywords: Roman Law; Roman Empire; Education.

\section{Resumen}

El Derecho Romano, uno de los resortes de la civilización occidental, consiste en el conjunto de normas vigentes en Roma, que durante los trece siglos de la historia romana. Regía la constante modificación en la estructura del Imperio Romano, según la evolución de la cultura y los cambios políticos, económicos y sociales, que lo caracterizan. El artículo pretende arrojar luz sobre la estructura y el funcionamiento de la educación romana. Para ello, se adoptó la investigación cualitativa, de revisión bibliográfica sistemática. Se concluye que la estructura comprende los dos grados tradicionales de gramática y retórica, en el curso de gramática se enseñan las lenguas latina y griega y las nociones precisas para ello, en el curso de retórica se enseña la interpretación de historiadores y oradores, las reglas y los ejercicios de elocuencia ocupan un lugar destacado, además los romanos supieron transmitir la práctica de los ideales de respeto a los derechos individuales y a la libertad política, del cultivo de la moral personal y colectiva, de la excelencia social que se llama cultura.

Palabras clave: Derecho Romano; Imperio Romano; Educación. 


\section{Introdução}

A palavra educação nos induz a pensarmos no processo ensino aprendizagem. Independente das teorias de ensino formalizadas por estudiosos, a máxima da educação é a aprendizagem.

Entretanto, a curiosidade em conhecer e entender o processo da educação no mundo tem estimulado cientistas a pesquisar sobre o tema e a escreverem textos, livros e toda soma de materiais que versem sobre a história até educação até os dias atuais (Viotto, 2016).

A sociedade romana é uma das mais antigas do mundo, nos trouxe a curiosidade de conhecer o processo de organização da educação. A sociedade brasileira teve muito de sua influência na estruturação da educação formal, a população brasileira é formada entre $60 \%$ a $80 \%$ por descendentes europeus, entre italianos, alemães, espanhóis, portugueses, entre outros povos, mas pouco se conhece da sua influência em nosso processo educacional (Del Vecchio et al., 2019).

Didaticamente, impõe-se a divisão no estudo do Direito Romano, colimando sua evolução interna, ou seja: o período arcaico da fundação de Roma no século VIII a.C. (800 a C. - 701 a.C.) até o século II a.C. (200 a.C. - 101 a.C.); o período clássico até o século III d.C. (300 a.C. - 201 a.C.) e o período pós-clássico até o século VI d.C. (600 a.C. - 501 a.C.) (Novo, 2018; Oliveira \& Boeira, 2019).

Cronologicamente, conforme o historiador de origem latina Tito Livus, a fundação de Roma aconteceu em 753 a.C. Entre o século VII a 509 a.C. a forma de governo foi a Monarquia. Com a queda do rei Tarquínio, de origem etrusca, Roma entra no período da República entre 509 a.C. a 27 a.C. e por fim o Império entre 27 a.C. a 476 d.C. (Gomes, 2021).

Conforme Cretella Junior (1995), os cidadãos romanos eram considerados mais como membros de uma comunidade familiar do que como indivíduos. A cidade de Roma era um labirinto de vielas estreitas e corredores, que ao anoitecer tornavase um ambiente violento. $\mathrm{O}$ estado não se responsabilizava pela segurança da população, que se organizava para garantir sua própria defesa. Os ricos se mantinham em suas camas, em casas luxuosas, cercados de escravos e cães de guarda (Berad, 2019).

Não obstante, o tradicionalismo romano fez com que o direito arcaico nunca fosse considerado como anulado. Dez séculos depois, o próprio Justiniano o considera com respeito. Em todo o Mediterrâneo, a conquista do poder pelos romanos exige uma evolução equivalente no campo do direito.

Roma foi uma sociedade que se organizava hierarquicamente, orientada por normas e papéis sociais rígidos em todos os estratos sociais. No lar, o pai tinha o papel de fornecer a educação. As mulheres romanas era serem incentivadas ao casamento arranjado pelo pai com apenas 12 anos, cuidar da família e comandar uma casa, ao não corresponder às expectativas da sociedade as mulheres sofriam constrangimento e abandono. As mulheres casadas podiam se envolver em brigas públicas para defender seus maridos. Nesse período, a alfabetização foi um privilegio das classes mais altas, as mulheres era reservado o espaço de suas residências, os assuntos reprodutivos e domésticos, sem acesso ao estudo (Viotto, 2016; Tolfo, 2018).

Os romanos lutaram em inúmeras guerras como a de Cartagno e as Guerras Púnicas, conquistaram territórios da Península Ibérica Gália e o Mediterrâneo Oriental. O império romano sofreu Influência de vários povos, pelo processo de expansão territorial pelo mundo, a partir de todo o ocidente (Europa e África) e em parte do oriente (Ásia). Os mercadores de escravos buscavam entre os povos derrotados "mercadorias" para comercializarem em Roma, homens e mulheres eram vendidos e serviam como criados, escravos, gladiadores, trabalhadores, contribuindo assim, para a economia do império. Roma foi uma oligarquia, com concentração de terras e riquezas nas mãos de poucos homens ricos e aristocratas (Del Vecchio et al., 2019; Gomes, 2021).

Assim, é possível averiguar que o Império Romano no período até 509 a. C., impôs usos e costumes nos territórios conquistados, mas também foi um caldeirão cultural pela presença de culturas tão diferentes em seu território. Roma foi berço 
da educação moral, cívica e religiosa. As ideias e experiências vivenciadas pelos fundadores do estado romano foram base para os romanos formalizarem, não somente a ordem jurídica da sociedade, mas a própria ciência do Direito.

Caracterizam o Direito do período arcaico romano o formalismo e a rigidez, a solenidade e a primitividade. O Estado possuía funções limitadas a questões essenciais para sua sobrevivência, tais como: guerra, punição dos delitos mais graves e a observância das regras religiosas. O Direito Romano existiu por doze séculos, ditando as normas, regras e o corpo jurídico do Estado (Correia \& Sciascia, 1953; Novo, 2018; Viotto, 2016). Posteriormente, a evolução caracterizou-se pelo acentuado e centralizado poder do Estado e, consequentemente, pela criação contínua de regras que sempre objetivavam reforçar mais a autonomia do cidadão, como indivíduo.

O marco mais importante e característico desse período é a codificação do direito vigente nas XII Tábuas, feita em 451 a.C. e 450 a. C. por um decenvirato, especialmente nomeado para esse fim (Novo, 2018). Em verdade, as XII Tábuas, denominadas séculos depois, como fonte de todo o Direito (fons oninis publici privatique juris), não forma nada mais do que uma reunião de regras provavelmente costumeiras, primitivas, e, por vezes, até cruéis.

À luz do magistério de Cretella Junior (1995), relacionado intimamente às regras religiosas, fixado e promulgado pela publicação das XII Tábuas, esse Direito primitivo representava um avanço na sua época. Aplicava-se exclusivamente aos cidadãos romanos.

Diante do exposto, compomos como pergunta de pesquisa: Como se estruturou e se formalizou a educação durante o Império Romano?

Muitas foram às contribuições dos romanos na arquitetura, no direito, na moda, na religião, na saúde, no calendário, na cidadania, nas obras públicas como na construção de estradas e saneamento básico, entre outras. É importante destacar a contribuição dos romanos na estruturação da educação formal e informal que conhecemos nos dias de hoje. O Direito Romano se constitui como uma série de ferramentas e mecanismos que contribuíram com os princípios da educação (Novo, 2018; Gomes, 2021).

Este artigo pretende projetar luz sobre a formalização da estrutura e funcionamento da educação romana durante o Império Romano.

Destarte, foi aqui que o gênio romano agiu de uma maneira peculiar para a atual mentalidade em relação à educação contemporânea.

\section{Metodologia}

Adotou-se a pesquisa qualitativa, de revisão bibliográfica integrativa. Os processos sociais precisam ser estudados e analisados pelos cientistas sociais, buscando compreender as condutas e os processos sociais que ocorrem na sociedade.

A pesquisa qualitativa estuda o fenômeno e a intensidade como ele acontece. Interessa-se pelas singularidades e seus significados, buscando em cada achado qualidade, ligando-os a sua dimensão sociocultural (Minayo, 2017). A pesquisa qualitativa defende o estudo do homem, levando em conta que este não é um ser passivo, diferentemente dos objetos, portanto necessita de uma metodologia que considere suas diferenças (Flick, 2009).

Este tipo de pesquisa pode ser utilizado em seus procedimentos metodológicos como a observação participante, entrevista individual ou grupal, história de vida, entre outros, levando sempre em conta o contexto social. A pesquisa qualitativa, também estuda as informações encontradas em documentos (livros, artigos, prontuários, jornais, entre outros), materiais arqueológicos, filmes, fotos, entre outras (Guerra, 2014). Segundo o autor, os elementos fundamentais no processo de investigação da pesquisa qualitativa são: a interação entre objeto de estudo e pesquisador; o registro dos dados ou informações coletados e a interpretação/explicação do pesquisador. 
O passado já foi visto como algo estático, fechado e rígido. Entretanto, o estudo da história é o estudo do próprio fato em um ponto do tempo (Appio et al., 2017). Assim, a revisão bibliográfica sistemática possibilita criar um embasamento teórico-científico sobre um tema histórico, um assunto ou um tópico, a partir de um protocolo específico e rígido selecionado pelo pesquisador (Galvão \& Ricarte, 2020). Os autores ressaltam as etapas a serem percorridas na revisão sistemática: delimitação da questão (tema do estudo, justificativa, pergunta de pesquisa, objetivos); seleção das bases de dados bibliográficos para consulta e coleta de materiais (critérios de exclusão, critérios de inclusão, palavras-chaves, bases de dados de pesquisa); elaboração de estratégia para busca avançada (emprego de operadores booleanos AND (e), OR (ou) AND NOT (e não)); sistematização e equipe (mecanismo e procedimentos de busca, dados a serem coletados nos documentos de pesquisa, software); seleção de textos e sistematização de informações levantadas (leitura flutuante de títulos, leitura de resumos, análise crítica dos documentos); apresentação dos resultados (relatórios científicos).

Optou-se por apresentar a pergunta de pesquisa e o objetivo do estudo na Introdução. Com a formulação desses itens, definiram-se os critérios do estudo. Os critérios de inclusão abrangem artigos, disponíveis na integra, publicados em língua portuguesa em periódicos entre 2010 e 2020, com busca utilizando as palavras-chave: "Direito romano"; "Império romano"; "Educação". Nos critérios de exclusão eliminou-se os estudos que não atendiam aos critérios de inclusãoUtilizou-se as fontes secundárias disponibilizadas on-line na Scientific Eletronic Library Online (ScieLO), Literatura Latino-Americana e do Caribe em Ciências da Saúde (LILACS) e Google Acadêmico para busca dos artigos publicados na íntegra, apresentando no título, resumo e/ou descritores as palavras-chaves elegíveis na pesquisa.

A busca dos artigos ocorreu entre janeiro e fevereiro de 2021. Os dados coletados (título, objetivos, método de pesquisa e resultados) foram anotados em planilha Microsolft Office Excel versão 12.0. Respeitou-se a autenticidade, a credibilidade, a integridade e o contexto das publicações.

$\mathrm{Na}$ análise documental buscou-se compreender os artigos e suas relações com as circunstâncias sociais e econômicas nos primórdios da educação romana. O método da revisão sistemática indicou o caminho percorrido nos documentos para investigação dos fatos da sociedade romana, datas dos acontecimentos e período sociocultural da educação romana.

Após leitura completa dos artigos encontrados, realizou-se a seleção das informações (semelhanças e diferenças) mais relevante sobre o tema de pesquisa e elaborou-se o relatório final com o título: Educação - a Roma Antiga.

\section{Educação - a Roma Antiga}

O território da Roma Antiga foi fundado em uma pequena região no Lácio, região central da Itália moderna e avança por várias regiões do mundo, formando uma civilização multicultural, complexa e sofisticada, com atores (plebeus e patrícios) de papéis bem definidos no seio social da sociedade. Os romanos desconfiavam de estrangeiros e por isso submetiam-nos socialmente a condições de inferioridade e escravidão.

O período da Monarquia compreende o século VIII a VI a.C. (753-509 a.c.), governada nesse período por um governante (rei), a economia de Roma se baseava na agricultura e pecuária. A sociedade romana era composta pelos patrícios (donos de terras, elite e políticos), plebeus (pequenos proprietários, comerciantes, produtores rurais e artesãos), clientes (agregados dos patrícios) e escravos (considerados como bens materiais) e proletariado (função de gerar a prole para compor exército romano) (Beard, 2019).

A família romana era considerada uma unidade política, jurídica, religiosa e econômica. A consanguinidade não era um aspecto importante na definição de família, criados e escravos também compunham a família. A se baseia nas Doze Tábuas criada em 451 a. C., que apresenta as tradições, princípios como a dignidade, a coragem, a firmeza, o espírito, os costumes e a disciplina. Propondo praticamente o esboço do código civil, com base na pátria potestas o "poder da vida e da morte" pelo pai 
ou chefe da família. O pater era pai, sacerdote, chefe e detentor do poder sobre a família, nem o Estado interferia em suas decisões (Cordeiro, 2016).

A educação acontecia em casa fornecida pelo pai (pater famílias), se aprendia o respeito e costumes ancestrais (mores maiorum), com consciência dos fundamentos da romanidade através do ensino do Direito, formando os civis romanus, com caráter civil, prático e familiar. A mulher cabia à educação e os cuidados da criança nos primeiros anos de vida, o papel de esposa, mães e cuidadoras da casa. O fim da educação romana é prático-social, ou seja, a educação visava à formação do agricultor, do cidadão, do guerreiro, entre outros (SoPedagogia, 2021).

Correa (2019) descreve que na literatura desse período surgem os primeiros registros latinos advindo da literatura grega clássica. A produção artística conta com poemas cantados e acompanhados de flauta (carmina conuiualia) apresentados em eventos da alta classe; lamentos cadenciados (neniae) entoados por mulheres assalariadas em funerais e a aproximação com a literatura grega com as composições de elogios (scipionum elogia) que coincide com a chegada das primeiras composições gregas em Roma. A educação formal romana inexistia, não havia intervenção do estado para sua criação, a educação estava voltada para o trabalha, incentivando que as crianças imitem soldados, agricultores, estadista, entre outros (Neves, 2018).

No século III ou meados do século II a.C. a educação romana já sofre influência social e cultural grega. O pai romano era considerado mestre de seus filhos, a educação acontecia essencialmente nos lares (Casagrande \& Mainardes, 2018). Roma já se encontrava contaminada pela Grécia, avançando à medida que se estabelecia a estrutura escravista, se apropriando de expressões culturais gregas. As trocas comerciais entre os povos faz com que o teatro com técnicas rudimentares das comédias e tragédias gregas, chegue a solo romano. $\mathrm{O}$ gênero poético dos literatos e a arte de escrever grega renovam a literatura romana.

A história da educação romana apresenta três fases principais, que compreendem: pré-helenista, helenista-republicana, helenista-imperial. Os princípios do helenismo cativam os romanos e influenciam a educação para o estudo da Filosofia e do Direito (Santarem, 2015).

No século II e I a. C. a fusão cultural dos gregos com a cultura oriental origina a cultura helenística, influenciando a educação romana e o conceito da formação integral do ser humano. Roma atinge seu apogeu na questão da expansão territorial.

No período da República (510 a.C.-27 a.C.) o poder em Roma é exercido pelo Senado através de dois cônsules, após a queda do último rei etrusco. O poder social e político exercido pelos patrícios beneficiam a exercerem cargos da magistratura romana, em detrimento de ascensão por parte da classe inferiorizada dos plebeus. (Almeida, 2021). A sociedade romana é agora composta pelos patrícios (ricos e políticos), plebeus (comerciantes, cavaleiros e pequenos proprietários), clientes (que serviam aos patrícios) e escravizados.

Marco Túlio Cícero (106-43 a.C.) cônsul, advogado, político, escritor, orador e filosofo romano imprimiu características práticas, originais e moralistas à pedagogia e à literatura romana, influenciado por filósofos gregos como Sócrates. As mudanças não foram tão fáceis de ocorrer, muitos romanos continuam simpáticos ao tradicionalismo. Entretanto, nesse período o patria potestas exclusivo do pater famílias foram sendo suavizado (Melo, 2006; Coelho \& Melo, 2013).

Os romanos constroem bibliotecas e teatros inspirados na cultura helênica, copiam a arte, a música, a pintura e a arquitetura grega. A antiga Paideia noção de educação das crianças no lar é ampliado e inserido princípios morais e noções de bons modos que continuam nos dias atuais. Alguns escravos gregos mais instruídos chegam a morar na casa dos patrícios, tomam o papel de preceptor/professor ensinando a ler e a escrever, a língua e a cultura grega aos filhos das famílias ricas. O programa de educação continha ainda disciplinas como geografia, história natural, religião, arquitetura, astronomia, gramática, matemática, retórica, filosofia, música e ginástica, havia o manejo de armas e exercícios físicos. A idade de 16 e 17 anos finaliza a educação doméstica (Andrade, 2020). 
Os meninos romanos de classes inferiores não tinham acesso a esses conhecimentos, crescendo sem instrução e trabalhavam na agricultura e na pecuária. As meninas tinham pouco direito ao ensino, continuam sendo preparadas para o casamento e os cuidados com o lar (Andrade, 2020).

O poder fragmentado e exercido pelos cônsules torna difícil governar, os romanos então decidem primeiro através do Triunvirato e depois com a figura de um Imperador, centralizar o poder e administrar o território.

O período do Império começa com a ascensão de Otávio Augusto (27 a.C. - 14 d.C.), o império assume seu apogeu com o senado e relativa estabilidade na sociedade romana. A verticalização do poder autocrático do Imperador torna as classes sociais compostas em: Patrícios (os que tinham privilégios políticos e regalias), Plebeus (comerciantes e os de cargo no governo), Clientes (trabalhadores e camponeses) e Escravos.

O mundo romano sofre várias transformações, a população se torna miscigenada (formando a base linguística de línguas como o português, espanhol, francês, italiano e romeno), nasce e avança o cristianismo (contrário ao politeísmo e a escravidão) e avança a expansão territorial. A riqueza e prosperidade de Roma faz com que aconteçam banquetes, festas, eventos esportivos e artísticos entre as classes privilegiadas, além da construção de inúmeros monumentos, arcos e edificações.

Os altos impostos cobrados, gastos com o exército para manutenção territorial e a desorganização econômica deixa o povo a própria sorte. $\mathrm{O}$ aumento da fome entre os camponeses, fez com que inúmeros rumassem para a cidade em busca de melhores condições de vida. Para evitar revoltas, durante a apresentação dos espetáculos públicos com gladiadores (Pão e Circo), o governo distribuía alimentos. Cada vez mais a estrutura econômica de Roma piora e fica mais difícil a distribuição de riquezas e a manutenção de uma sociedade estática (Coelho \& Melo, 2013).

A educação para os filhos da elite romana prospera influenciada pelo processo de helenização, o Estado cria um sistema de ensino formal e oficial centralizado que atende os filhos das classes privilegiadas e ricas, preparando-os para participação ativa na vida pública romana e no corpo burocrático resolutivo para as questões administrativas do império. (Melo, 2006; Corrêa, 2019). Para a elite romana viver é mais do que um ato biológico, a elite precisa ser educada para a vida pública e, portanto, para a oratória. O orador não podia se refugiar apenas no estudo da doutrina da oratória, o orador necessita da prática da vida pública, sem ela não e faz um orador (Vasconcelos, 2000).

Os meninos levam para a escola uma maleta contendo tinteiro, penas para escrita e cadernos de madeira. A criança caminhava para a escola acompanhada por um escravo grego, que a aguardava até as aulas encerrarem, trazendo-a para casa em segurança. O escravo grego cuidava de seus bons modos e da sua moral. Observa-se nessa relação à diversidade cultural e saberes de pessoas com diferentes níveis socioeconômicos em um momento de construção de conhecimento e educação (Lima et al., 2020).

A educação se estabelecia culturalmente denominada "cultura greco-romana", com ensino da retórica, gramática e dialética, formando um homem de ação, orador e culto (Garcia, 2011). Os rapazes romanos as famílias abastadas avançavam para o ensino secundário (Pimenta, 2014). Quando um jovem romano ganhava a toga virilis ele passava a ser cidadão e podia escolher estudar filosofia em Atenas ou Rodes, como César, Cícero, Otaviano e Horácio (Melo, 2006; Correa, 2019).

A desigualdade social acontecia no acesso à educação, apesar da influência grega na sociedade romana, o Estado não absorve a preocupação de oportunizar a educação para todos os romanos igualmente. Os meninos plebeus recebiam educação informal fornecida pelo pai em casa com ensino do cálculo e escrita, sem nenhum desses apetrechos e preparando-os para o trabalho. (Coelho \& Melo, 2013; Corrêa, 2019; Andrade, 2020).

A educação romana promovia a desigualdade entre os sexos e a situação econômica dos romanos (Pimenta, 2014).

A cultura permanece com influência de aspectos do helenismo sem destruir as virtudes romanas, entretanto a educação não merece o mesmo tratamento. As propostas educacionais avançam baseadas no Estoicismo (princípios morais 
rígidos) e no Epicurismo (materialismo e prazeres), correntes filosóficas gregas do período helenístico vividos pelos romanos naquele momento (Coelho \& Melo, 2013).

Durante o império o governo tentou promover a educação como uma responsabilidade do Estado, entretanto os romanos, diferentemente dos gregos, priorizam o conhecimento prático e organizador, ignorando a teoria, o especulativo e à paixão intelectual. Culturalmente os romanos foram um povo atrasado quando se compara com a paixão intelectual e artística do povo grego. A educação, para os romanos, tinha como finalidade preparar para a vida e o trabalho (Melo, 2006; Coelho \& Melo, 2013).

Diante dos princípios que a educação é função da família (pai e mãe), do pátrio poder com responsabilidade na formação do romano, se explica em parte a negligência do Estado em relação ao sistema educacional formal. Com os conservadores contrários à helenização da vida romana, os censores publicavam um decreto que condenava a escola latina de retórica (92 a. C.), que era considerada uma novidade contrária aos costumes e aos preceitos dos maiores. Com a influência da cultura grega na sociedade romana, a educação galgou espaço além das casas, sendo realizada nas escolas privadas (Melo, 2006; Santos, 2015).

Antes do Império os romanos tiveram iniciativas tímidas de edificar escolas municipais. Os romanos estruturam o primeiro sistema de ensino centralizado, com várias instituições de ensino espalhadas pela província sob a intervenção do Estado. O papel intervencionista do Estado era importante para a administração do Império, com uma boa máquina administrada por funcionários com pouca instrução. No início o Estado pouca intervia na educação, depois passou a subvenciona-la e finalmente exerceu a responsabilidade da educação romana através da legislação.

A primeira escola romana pública foi edificada em 449 a.C., lugar onde famílias menos abastadas mandam seus filhos para serem educados por antigos escravos e velhos soldados, que se prestam em ensinar em um espaço alugado chamado pergula (loja de instrução). Havia bancos e cadeiras, materiais como cubos, esferas e alguns mapas, os alunos aprendiam o texto das Doze Tábuas (Melo, 2006).

As escolas privadas evoluem com quatro níveis de ensino: a de ensino elementar ou ludi magister ensinava ler, escrever e calcular; a secundária ou de gramática tinha ensino literário em latim e grego, ensinava linguagem, gramática, métrica, estilo e conteúdos de poemas; a escola complementar ou de retorica e a superior ou Ateneu (Medicina, Direito, Mecânica, Arquitetura, Engenharia, Filosofia, além de dança, pintura, escultura, artesanato, etc.), todas continuam sobre a supervisão do Estado. Toda essa influência rendeu frutos, romanos importantes se expressavam e escreviam em grego (Melo, 2006; Garcia, 2011, Corrêa, 2019).

O trabalho do professor em comparação a outra atividade era considerado inferior, muitas vezes precisavam complementar a jornada de trabalho e o salário com outra atividade laboral. A época das relações sociais e o magistério em Roma aconteciam m pela venda do trabalho imposta por um sistema econômico produtivo, sem a valorização do ser profissional. (Carvalho \& Cavalcanti, 2020). Pouco se sabe sobre os métodos de ensino, talvez fizessem uso de exercícios de tradução. Inicialmente, foram traduzidas para o latim as obras literárias e poéticas gregas, como a Odisseia. Depois estudaram os autores gregos no texto original, formando aos poucos uma literatura nacional romana sobre o modelo formal da literatura grega (Melo, 2006; Corrêa, 2019).

No baixo império, preocupado que os cristãos assumissem o ensino em Roma, o Imperador Justiniano (332-363 a.C.) toma a decisão de nomear os professores, um ato de intervenção do Estado no sistema educacional romano. Também determina que os melhores retóricos e gramáticos assumam a educação dos jovens romanos (Melo, 2006).

O interesse imperial pela cultura e sua difusão é vislumbrado como uma importante ferramenta de romanização dos povos, com poder de penetração e de expansão da língua e do jus romano, engrandecendo assim o império. A cultura, de 
maneira modesta, se espalhou para povos como a Espanha, a Gália, a Grã-Bretanha, a Germânica, as províncias danubianas e a África setentrional. Algo inimaginável ser alcançado pelo helenismo (Santos, 2015).

Com a decadência do império romano termina a tradição do ensino laico, sobrevivendo apenas na transmissão da mensagem cristã. $\mathrm{O}$ sistema educacional romano inspirou outros povos do ocidente na organização da estrutura educativa (Melo, 2006).

O fim do Império romano acontece em 476 d.C. com a queda do último imperador e a invasão do lado ocidental por Odoacro rei do povo germânico. A parte oriental continua existindo com o nome de Império Bizantino.

\section{Considerações Finais}

A educação no território romano acontecia conforme as necessidades de Roma. Os romanos eram educados para as necessidades imediatas, práticas da vida e para o trabalho. Os oriundos da classe aristocrática eram preparados para o mundo político e a vida pública, os plebeus geravam os futuros soldados para defender e avançar nas conquistas territoriais de Roma, cada qual com seu papel específico. A vida do romano pertencia a Roma e era colocada a serviço da pátria.

Os romanos trouxeram inúmeras contribuições, destaque para a formalização de um sistema educacional formal gerenciado pelo Estado, organizado em escolas públicas nas diversas esferas governamentais, permitindo o acesso de crianças e jovens de todas as camadas da população.

O povo grego formado por uma população culta, amante da arte, da filosofia e da oratória, encontram no povo romano a praticidade, a organização e o imediatismo da formação para a vida e o trabalho. A educação romana manteve peculiaridades intrínsecas, que repassou como valores à humanidade.

Os estudos sobre a educação precisam avançar, sugerimos aos pesquisadores que se debrucem no estudo na evolução do processo educacional em outras civilizações, além dos seus reflexos nas ações e estratégias utilizadas, na atualidade, pelos docentes no processo comunicacional com os discentes.

Em âmbito maior, pode-se dizer que os romanos ainda souberam, com seu senso pragmático, transmitir instrumentos eficazes às instituições no mundo para a prática dos ideais do respeito aos direitos individuais e à liberdade política, do cultivo da moralidade pessoal e coletiva, e, enfim, da excelência social a que se denomina cultura.

\section{Referências}

Almeida, M. E. (2021). A educação na Roma antiga. Revista Anthesis, 9 (17), 24-36. https://periodicos.ufac.br/index.php/anthesis/article/view/3584

Andrade, A. L. M. S. (2020). Educação na Roma antiga. https://www.infoescola.com/historia/educacao-na-roma-antiga

Appio, J.; Frizon, N. N.; Canof, L.; Marcon, D. \& Madrugada, B. (2017). Pesquisa Histórica como uma possibilidade à pesquisa em Estudos Organizacionais. $\begin{array}{lllll}\text { Congresso Ibero-Americano em } & \text { Investigação } & \text { Qualitativa } & \text { (CIAIQ), }\end{array}$ https://proceedings.ciaiq.org/index.php/ciaiq2017/article/view/1175/1137

Berad, M. (2019). Os perigos, vícios e diversões da vida noturna na Roma antiga. BBC NEWS BRASIL. https://www.bbc.com/portuguese/geral-47713000

Carvalho E. Q. \& Cavalcanti, R. J. S. (2020). Inclusão na educação profissional e tecnológica: abordagem emancipatória do trabalho educativo. Research, Society and Development, 9(5), e115953219. https://doi.org/10.33448/rsd-v9i5.3219

Casagrande, R. C. \& Mainardes, J. (2018) História da educação e da deficiência permeada por uma reflexão epistemológica: da educação primitiva à romana. Revista Educação Especial em Debate, Vitória, 3(6), 137-155. https://periodicos.ufes.br/reed/article/view/23631

Coelho, J. P. P. \& Melo, J. J. P. (2013). Educação, poder e cidadania na Roma antiga: algumas considerações sobre a formação do governante. História e Perspectivas, Uberlândia, (49), 537-560. http://www.seer.ufu.br/index.php/historiaperspectivas/article/view/24997

Cordeiro, M. N. A. (2016). A evolução do pátrio poder - poder familiar. Blog Conteúdo Jurídico. http://conteudojuridico.com.br/consulta/Artigos/46470/aevolucao-do-patrio-poder-poder-familiar

Corrêa, E. F. S. (2019). Práticas educativas e escolares na Roma antiga. Principia, Rio de Janeiro, 39, 61-69. https://www.epublicacoes.uerj.br/index.php/principia/article/view/47438 
Correia, A. \& Sciascia, G. (1953). Manual de direito romano. (2a ed.), Saraiva.

Cretella Júnior, J. (1995). Curso de direito romano. (19a ed.), Forense.

Del Vecchio, F B.; Dias, B. C. \& Tuchtenhagen, A. X. (2020). O movimento na luta pela vida: sistema de organização e treinamento de gladiadores. Motrivivência, Florianópolis, 31 (57), e55655. https://periodicos.ufsc.br/index.php/motrivivencia/article/view/2175-8042.2019e55655/39011

Flick, U. (2009). Desenho da pesquisa qualitativa. Artmed.

Galvão, M. C. B. \& Ricarte, I. L. M. (2020). Revisão sistemática da literatura: conceituação, produção e publicação. LOGEION: Filosofia da informação, Rio de Janeiro, 6(1), 57-73. https://sites.usp.br/dms/wp-content/uploads/sites/575/2019/12/Revis\%C3\%A3o-Sistem\%C3\%A1tica-de-Literatura.pdf

Garcia, A.S. (2011). A educação romana e o destino do latim peninsular. Soletras, São Gonçalo, ano XI(21), 7-21.

Gomes, C. (2021). Roma antiga (monarquia, república e império). https://www.infoescola.com/historia/roma-antiga-monarquia-republica-e-imperio/

Guerra, E. L. A. (2014). Manual de pesquisa qualitativa. https://docente.ifsc.edu.br/luciane.oliveira/MaterialDidatico/P\%C 3\%B3s\%20Gest\%C3\%A3o\%20Escolar/Legisla\%C3\%A7\%C3\%A3o\%20e\%20Pol\%C3\%ADticas\%20P\%C3\%BAblicas/Manual\%20de\%20Pesquisa\%20Quali tativa.pdf

Lima , H. F.; Amaral, J. A.; Sacramento, R. A. L. \& Costa, E. (2020). Reflexões sobre o "projeto encontro de saberes" enquanto experiência teóricometodológica pós-colonial e da ecologia de saberes no ensino superior. Research, Society and Velozmente, Vargem Grande Paulista, 9 (7), 1-19. https://rsdjournal.org/index.php/rsd/article/view/4525/4041

Melo, J. J. P. (2006). A educação e o estado romano. Revista UDESC, Florianópolis, 7 (2), 1-19. https://revistas.udesc.br/index.php/linhas/article/view/1331

Minayo, M. C. S. (2017). Amostragem e saturação em pesquisa qualitativa: consensos e controvérsias. Revista Pesquisa Qualitativa, 5 (7), 1-12. https://editora.sepq.org.br/rpq/article/view/82/59

Neves, A. C. A. S. (2018). Mos maiorum e a formação do cidadão ideal na república romana. Revista Historiador, Porto Alegre, ano 11(11), 7-15.

Novo, BN. (2018). Direito romano. Blog jus.com.br. https://jus.com.br/artigos/65952/direito-romano

Oliveira, J. A. A. \& Boeria A. (2019). A evolução da história do direito romano. Diálogos e Interfaces do Direito - Revista Científica do Curso de Direito, Cascavel, 2, (2), 40-55. https://www.fag.edu.br/revista/dialogoseinterfaces/66

Pimenta, L. P. (2014). “Vimqve omnem hvmanitatis”: o modelo pedagógico romano. Direito \& Justiça, Porto Alegre, 40(1), 39-45. https://revistaseletronicas.pucrs.br/index.php/fadir/article/view/16547

Santarem, M. L. G. (2015). Faculdade de Direito de Caxias do Sul/RS: indícios da história e da cultura acadêmica (1959-1967). Dissertação de mestrado, Universidade de Caxias do Sul, Caxias do Sul, RS, Brasil. https://repositorio.ucs.br/xmlui/bitstream/handle/11338/1151/ Dissertacao\%20Michelle\%20Luisa\%20Grezzan a\%20Santarem.pdf?sequence=1\&isAllowed=y

SóPedagogia. (2021). História da educação - período romano. Virtuous tecnologia a Informação, 2008-2021. https://www.pedagogia.com.br/historia/romano.php

Tolfo, S. (2019). A representação de mulheres romanas e seus epitáfios. Alétheia - Estudos sobre e Antiguidade e Medievo, Jaguarão, 1(1), 1-20. https://periodicos.unipampa.edu.br/index.php/Aletheia/article/view/118

Vasconcelos, B. A. (2000). Educação oratória no de oratore de Cícero. Letras Clássicas, 4, 179-190. https://www.revistas.usp.br/letrasclassicas/article/view/73787

Viotto, R. A. (2016). História da educação: da antiguidade aos nossos dias. Nuances: estudos sobre Educação, 27(1). 357-363. https://revista.fct.unesp.br/index.php/Nuances/article/viewFile/4389/3311 